\title{
Humanities-oriented Teachers' Scientific Research Performance Evaluation System in Missouri State University and Its Enlightenment*
}

\author{
Ermi Zhang \\ School of Humanities and Law \\ Northeastern University \\ Shenyang, China 110189
}

\author{
Wanbing Shi \\ Special Education Research Center \\ Nanjing Normal University of Special Education \\ Nanjing, China 210038
}

\begin{abstract}
American colleges and universities have established a complete and rigorous humanities-oriented teachers' scientific research performance evaluation system to ensure the quality of higher education. Teachers' scientific research performance evaluation refers to the evaluation on teachers' performance in scientific research work and putting forward suggestions and planning for teachers' future scientific research development provided that teachers' scientific research work level has been known. Taking Missouri State University as an example, this paper makes a detailed introduction of relevant status of the evaluation system from six perspectives such as the evaluation subject, evaluation object, evaluation purpose, evaluation standard, evaluation rules and evaluation method, with a view to provide reference for humanities-oriented teachers' scientific research performance evaluation in Chinese colleges and universities.
\end{abstract}

Keywords-USA; colleges and universities; humanities; teacher's scientific research performance evaluation system; enlightenment

\section{INTRODUCTION}

As early as in 1930s, Mei Yiqi, the former president of Tsinghua University, had already put forward the famous statement of "The so-called university lies in the quality of teachers[1]", which shows that whether a university is excellent or not depends on the quality of teachers. With the rapid development of economic construction, having firstclass teachers has become the core goal of the development of many universities in China. Many colleges and universities have begun to shift their focus of work to internal construction of the school, especially regarding the management on teachers' scientific research as the key task of the internal construction. Even so, there is a gap between teachers' scientific research management and the overall development level of colleges and universities, especially as reflected in the evaluation on humanities-oriented teachers' scientific research performance. As the major of humanities has its particularity, it is inevitable to encounter resistance in making evaluation on relevant scientific research performance. Therefore, Chinese colleges and universities

*Fund: Results of the Education Program of National Social Science Fund (Project No.: BFA150043). should learn from developed countries such as America to overcome difficulties encountered in scientific research management. This paper takes Missouri State University as an example and explores the advantages and characteristics of American public universities in aspect of evaluation on humanities-oriented teachers' scientific research performance, in order to provide somewhat enlightenment for Chinese colleges and universities.

\section{INTERPRETATION OF THE STATUS OF THE}

HUMANITIES-ORIENTED TEACHERS' SCIENTIFIC RESEARCH PERFORMANCE EVAlUATION SySTEM OF Missouri STATE UNIVERSITY

Missouri State University, formerly a normal school, has enjoyed a good reputation in the north central of United States for many years. Its teachers' scientific research performance evaluation system is being improved day by day. The school's humanities related institutions are divided into two levels: the first level is college, namely the College of Arts and Letters, the College of Humanities and Public Affairs, and the College of Business; the second level is department affiliated to the college, such as the Arts and Design Department, the English Department, the Department of Media, Journalism and Film, and the Modern and Classical Languages Department, the Music Department, the Theatre and Dance Department, the History Department, the Philosophy Department and the Religious Studies Department affiliated to the College of Arts and Letters, as well as the Department of Merchandising and Fashion Design affiliated to the College of Business. In the school, the scientific research performance evaluation system for humanities-oriented teachers is almost the same as that for other majors of teachers, but is somewhat different from fine arts, design, drama and dance and the like majors in aspects of evaluation standard and method. Teachers of the said majors are not like other majors of teachers engaging in a large number of writing work, but engage in creative activities such as art exhibitions and stage drama performances. Such artistic achievements should be the same as the scientific achievements of other majors of teachers, incorporated into the evaluation indicators. Relevant policies on the humanities-oriented teachers' scientific research 
performance evaluation in Missouri State University are sourced from the "Missouri State University Faculty Handbooks". In the policies, it is emphasized that humanities-oriented teachers must be "dedicated to achieve success in scientific research" and "realize professional development in such a solid platform as school". The school's scientific research performance evaluation is mainly divided into three categories: annual evaluation, promotion and lifelong appointment evaluation, and post-tenure evaluation. The next explains the humanities-oriented teachers' scientific research performance evaluation system (hereinafter referred to as the Evaluation System) of Missouri State University from six starting points: evaluation subject, evaluation object, evaluation purpose, evaluation standard, evaluation rules and evaluation method.

\section{A. Evaluation Subject}

The Evaluation System of Missouri State University collects evaluation data from multiple subjects. The evaluation subjects include the president and provost, the personnel committee, dean \& department chair, peer reviewer, colleagues and the teacher himself. At Missouri State University, the evaluation on teachers' scientific research performance is mainly the responsibility of the personnel committee. The committee is provided with temporary special evaluation team in each college, and is also an important part of the peer evaluation of teachers in the school.

First, provost is the chief academic officer of the school, assisting the president in charge of various scientific research activities of the school, such as formulating scientific research policies and supervising scientific research activities. Specifically, he is responsible for formulating the annual scientific research performance evaluation schedule, evaluation materials and related lists of the three colleges and 10 departments related to the humanities, giving conclusive suggestions on the evaluation results, and finally providing reference opinions to the president and the board of directors.

Second, like most American colleges and universities, Missouri State University has high degree of right of autonomy in personnel management. The personnel committee is the highest evaluation agency for teachers' scientific research performance and is provided with branch in each college to make autonomous management on the humanities-oriented teachers' scientific research performance evaluation related affairs. The personnel committee is mainly responsible for providing evaluation report to the evaluated teacher, and then giving evaluation suggestions according to the report content, for the reference of the college and department leaders.

Third, leaders of college and department are the primary links in the evaluation subject, and can obtain the first-hand evaluation information. Department chair is responsible for collecting evaluation materials of teachers. Dean is responsible for submitting evaluation letter to the peer experts outside the school, and after the experts giving suggestions, making the first round of evaluation on the teachers in combination with the beneficial parts of the suggestions. Dean and department chair should not only cooperate with the personnel committee to do internal evaluation, but also need to report the evaluation progress to the provost, and can be called the "first responsible person" of the entire evaluation subject.

Fourth, as the "focus" of humanities-oriented teachers' scientific research performance evaluation, peer experts are served by off-campus experts and on-campus peers. Wherein, on-campus peers has higher power; no matter in annual evaluation or promotion or lifelong appointment evaluation, peer experts play the crucial decision-making role. Generally, more than 20 peer experts who are well-respected in the industry and have no interest relationship with the evaluated teachers will be invited by the evaluation committee of the personnel committee to anonymously review the papers, monographs and performances of the evaluated teachers and give written opinions.

Fifth, teachers are the "protagonist" of the scientific research performance evaluation of Missouri State University. The school gives teachers high degree of autonomous right in the evaluation process. The evaluated teachers need to fill out self-evaluation form, detailing the scientific research results obtained in the past 3-6 years. The content mainly should be spread on the basis of the scientific research objectives, scientific research performance and planning for future scientific research work. As the person who knows the most about his scientific research situation, teacher himself is more likely to give full play to the advantages and avoid the deficiencies in the evaluation process.

\section{B. Evaluation Object}

The object of the humanities-oriented teachers' scientific research performance evaluation (hereinafter referred to as the Evaluation) of Missouri State University is the evaluated teachers and their research and creation activities. Wherein, the evaluated teachers refers to all full-time and part-time lecturers, assistant professors, associate professors and professors; the research and creation activities mainly include scientific research projects and scientific research achievements and so on. Especially when evaluating teachers majoring in arts such as fine arts, design, dance and drama, the creative achievements such as awards for dance competitions and film works should also be considered as part of their scientific research achievements [2].

\section{Evaluation Purpose}

The purpose of the Evaluation of Missouri State University is to get college and university leaders known about teachers' scientific research status so as to provide reference for evaluation on teachers' promotion and salary increase and timely find any research problems existing in teachers themselves and give applicable assistance, and further promote teachers' professional development and improvement the school's running quality. The Evaluation is a process of continuous communication with leaders of the university. The specific objectives can also be summarized as follows: first, to evaluate the efficiency of each teacher in 
performing scientific research duties; second, to identify the factors available to improve scientific research performance; third, to explain the performance standards relevant to the current position; fourth, to assist teachers in developing additional research knowledge and research skills to promote the development of their research work; fifth, to identify the particularity of art teachers' research work; sixth, to record teachers' unqualified scientific research performance and provide opinions for improvement; seventh, to determine the retention of teachers after the end of the probation period; eighth, to determine teachers' demand for receiving scientific research training; ninth, to set up specific goals related to scientific research work and follow it up in real time.

\section{Evaluation Standard}

The standard of the Evaluation of Missouri State University is based on the school-running mission and academic mission of the school, and abides by the principles of academic freedom, multiple cultural perspectives, and equal opportunities for scientific research. By levels, the evaluation standard can be divided into title standard, college and department standards, and school standard. Different level of evaluation standard has different specific requirement. Also, different colleges have different evaluation standards as their education focuses are different due to the difference in major. The major of arts firstly attaches importance to teachers' creative practices such as performances and exhibitions, while other majors focus on writing work. The above evaluation standard of the school can further be broken into specific evaluation indicators. The indicators can be divided into two levels. Wherein, the first level of indicators includes evaluation of scientific research projects and evaluation of scientific research results. The second level of indicators can be further divided into two parts: The first part is the fund and nature of a scientific research under the evaluation of scientific research projects; the second part is the award status, influence depth, academic papers and publications under the evaluation of scientific research results [3].

\section{E. Evaluation Rules}

The rules for the Evaluation of Missouri State University mainly include democratic appraisal rules, confidentiality rules and evaluation result appeal rules. The democratic appraisal rules stipulate that in the year of salary adjustment (excluding scientific research performance factors), full-time teachers have the right to abandon the review of the personnel committee by voting. In the year when scientific research performance evaluation is required, the evaluated teachers ought to have the right to know the evaluation results; and each teacher should be arranged to meet directly with the department chair to discuss the specific content of the annual evaluation and formulate the research goals for the coming year. Confidential rules mainly mean that it is necessary to maintain the evaluation information confidential during the entire evaluation; relevant personnel of the school and each college and department must be brave enough to assume their personal responsibilities and ensure not violating the confidential agreement for scientific research performance evaluation as formulated by the school. The evaluation result appeal rules stipulate that if the evaluated teacher is dissatisfied with the evaluation result, he can apply for reconsideration through the Academic Personnel Grievance Process (APGP) and submit the application together with relevant supporting materials to the personnel committee. The appeal request proposed by the teacher and the response given by the personnel committee shall be further submitted to the Dean and, if not resolved, to the Provost. If the Provost disagrees with the teacher's appeal, he shall send the teacher a written explanation of the reason for refusing the appeal [4].

\section{F. Evaluation Method}

In the process of the Evaluation of Missouri State University, it mainly adopts qualitative and quantitative integrated evaluation method, namely the evaluation is mainly made in peer evaluation method and associated with achievement counting method and citation analysis. Peer evaluation method is a common method for humanitiesoriented teachers' evaluation and mainly involves three parts: external experts, on-campus peers and evaluation committee. The evaluated teacher, department chair, and personnel committee may jointly selected four off-campus experts to make the evaluation. If the teacher and department chair could not reach an agreement on the candidate, they should respectively select two chose two off-campus experts to make the evaluation. The selection list should be finally submitted to the Dean, and the Dean should then prove that the selection process is in line with the evaluation principle before contacting the off-campus experts. Results counting method is a common quantitative evaluation method, and mainly measures the performance of the evaluated teachers on the basis of the quantity of scientific research results. This evaluation method is very popular in other majors, but in the humanities related major it can only be used as an aid. In the process of use, this method mainly has two calculation methods: direct sum of academic papers, monographs and so on, and counting in weighting method. As one of the important methods of bibliometrics, citation analysis is another quantitative method often used in the Evaluation. The status of being cited of the evaluated teacher's thesis and monograph can be regarded as a factor to measure the scientific research level of the teacher. At the same time, it also reflects the scientific research influence and academic status of the teacher in the field of the major from the perspective of citation of scientific research results. Therefore, the citation data provides a quantitative basis for the Evaluation [5].

\section{MAIN CHARACTERISTICS OF THE EVALUATION SYSTEM FOR AMERICAN COLLEGES AND UNIVERSITIES}

Above all, Missouri State University has a rigorous evaluation process and comprehensive evaluation indicators and hence provides institutional guarantee for the orderly conduct of evaluation activities. Relevant policies also form a distinctive evaluation system for the school. To a certain extent, it also plays a representative role in the Evaluation in American public colleges and universities. The main features are as follows: 


\section{A. Teachers Have Autonomous Right in School Management}

Missouri State University encourages humanitiesoriented teachers to become participants and decision makers in relevant scientific research performance evaluation, to ensure the scientific research status of teachers in the school and further consolidate the scientific research quality of the school. The school strongly supports teachers to personally participate in the evaluation and to be the master of the school rather than just "office worker" of the school, and get those who work in front line of teaching work and are familiar with teachers' work participated in administration to avoid outflow of the scientific research management right and eventually ensure the stable improvement of the schoolrunning level.

\section{B. The Evaluation Activity Should Treat the Professional Development of Teachers as the Wind Vane}

In the short term, the purpose of the Evaluation in colleges and universities is to provide reasonable and effective basis for making decision on teacher's promotion and salary increase; in the long term, it is to provide a clear goal for professional development of teachers. As a separate group, Missouri State University's humanities-oriented teachers have academic characteristics and scientific research results different from other majors of teachers. Therefore, the school does not simply copy the scientific research performance evaluation system for other majors of teachers, but separately designs a flexible and diverse evaluation system for humanities-oriented teachers in a customized way. For this reason, the setting of the evaluation purpose is flexible to some extent and refuses to copy the evaluation mode of other majors, but basically start from the professional development of teachers and get the evaluation indicator closely linked to the evaluated teacher's scientific research ability level by level.

\section{Relevant Rules Are Extremely Strict and Impartial}

The success of teachers' scientific research performance evaluation is closely related to its strict rules and regulations. Missouri State University has very complete rules for the Evaluation; the evaluation process is fair, and the evaluation rules are transparent, thus ensuring the purity of the evaluation activity. For example, the school implements scientific research performance evaluation result appeal rules. By this rules, the evaluated teacher has the right to doubt the evaluation result and submit written opinions to the human resources department within 10 working days, requesting get this written opinions placed in the personnel files. The human resources department can also provide reference opinion on or ask questions about the expected scientific performance evaluation standard, and assist the teacher to make appropriate adjustment on the research activities in the next few years based on the evaluation results. Regardless of the specific evaluation rule, the following provisions should be abided by without exception: it is prohibited to discriminate against teachers for reason of their gender, race, skin color, religion, nationality, blood lineage, age, disability or veteran status, or give unfair treatment on those teachers having special family background and marital status; the offenders will be punished according to relevant regulations.

\section{THE ENLIGHTENMENT OF THE EVALUATION SYSTEM FOR AMERICAN COLLEGES AND UNIVERSITIES TO CHINA}

The Evaluation is treated as the "leader" to promote the professional development of teachers, hence whether the Evaluation is scientific or not directly relevant to teacher's positive and negative coordination with the school's management. On this basis, the following three suggestions are proposed for Chinese colleges and universities with reference to the Evaluation System of Missouri State University:

\section{A. Vigorously Advocating the Concept of "Faculty} Governance" and Improving College Teachers'

Discourse Power in the Scientific Research Performance

\section{Evaluation}

College teachers are the people who know the most about scientific research and the content of scientific research performance evaluation. However, humanities-oriented teachers in colleges and universities in China do not have sufficient autonomous right in relevant scientific research performance evaluation, and do not coordinate with the evaluation work that highly. In contrast, in public universities in the United States, the evaluated teachers have absolute voting rights in the process of scientific research performance evaluation. Hence, it is needed to improve the academic committee centered academic management system and organizational framework, and improve the working mechanism of having teachers, students and employees participated in democratic management and supervision, so as to further construct a systematic, complete, scientific, normalized and effectively operated university governance rules system, boost the modernization of college's governance system and capacity, contribute Chinese wisdom and scheme to the modern development of colleges and universities and provide an institutional support and guarantee for realizing China's goal of strengthening the country by higher education [6].

\section{B. Improving College Teachers' Performance Evaluation and Taking the Promotion of Professional Development of Teachers as the Primary Goal}

As one of the core contents of human resources management in colleges and universities, the Evaluation refers to using qualitative and quantitative integrated evaluation method to make a scientific comparison and analysis and a real, reliable and fair authoritative judgment on the evaluated teacher's scientific research input, output and results in a certain period of time. In view of this, teachers' scientific research performance evaluation is not only a basis for making decision on teachers' salary increase and promotion, but also a basis for making analysis on teachers' scientific research performances in recent years and further awarding performance-excellent teachers in aspects of economy or position and criticizing or helping performance-poor teachers to stimulate the scientific research development potentials of teachers and finally 
enhance the overall scientific research strengths of the school [7].

\section{Implementing Strict Management on College Teachers to Ensure the Purity of College Teachers}

The humanities-oriented teachers are the foregoers striving at the front line of scientific research in colleges and universities, and their scientific research quality directly affects the school-running quality of the university. In terms of institutional construction, colleges and universities should, focusing on improving the quality of scientific research, make overall planning and adjustment on the teacher recruitment rules, performance evaluation rules and job title promotion rules, and improve the rules for the Evaluation in colleges and universities. Besides, it is needed to attach importance to scientific research work, pay attention to improving the proportion of scientific research achievements in teachers' performance evaluation, and establish a mechanism linking scientific research funds with the quality of teachers' scientific research work to mobilize teachers' enthusiasm in making scientific research. More importantly in China, while improving college teachers' performance management and improving their economic income and social status, it is also necessary to implement strict management on college teachers, and set up a red line system to absolutely remove unqualified teachers, put to an end any behavior in violation of teacher's professional ethics. It is to guarantee posing equal stress on integrity and ability of college teachers by strict institutional management [8].

\section{CONCLUSION}

Looking at the overall construction of the Evaluation System of Missouri State University, it is not difficult to find the following problems: the scientific research performance and evaluation and its evaluation method and evaluation indicators adopted in public universities in the United States have reached the world's leading position, and they are becoming more and more rational, scientific and complete; however the Evaluation level in Chinese colleges and universities still lags behind that in western developed countries to certain extent. The creativity, complexity and exploratory nature of scientific research activities bring great difficulties to the evaluation work. There are still many obstacles in the construction process of the Evaluation System in China. For example: teachers lack the right to speak in school management; the evaluation activities are mainly for making decision on reward and punishment; and the evaluation rules lack strictness and impartiality. Those aspects are worth of further research and discussion by scholars and researchers.

\section{REFERENCES}

[1] Mei Yiqi. Autobiography of Mei Yiqi [M]. Hefei: Anhui Literature and Art Publishing House, 2013: 11-14. (in Chinese)

[2] Periodic Review of Reappointment (or Renewal of Contract). Tenure, Promotion Guidelines: College of Business, Missouri State University (2017) [S]:1-13
[3] Tenure, Promotion and Annual Evaluation Guidelines: College of Arts and Letters. Missouri State University (2017) [S]: 1-6.

[4] Missouri State University's Faculty Handbook: Chapter 4 Faculty Evaluation (2018) [S]: 30-51.

[5] Moed H F. Citation Analysis in Research Evaluation [J]. Information Science \& Knowledge Management, 2005, 57 (1): 13-18.

[6] Zhang Wei. Faculty Governance and University Governance [J] Research on Higher Education, 2018, 39 (06): 51-58. (in Chinese)

[7] Tiehua Qu, Supervisor D, At P, et al. University Teacher's Professional Development Theory Based on Academic Attribute [J] Educational Research, 2009: 62-65.

[8] Liu Xin, Wang Xuyang. The practice of teacher performance management in American research universities and its enlightenment [J]. Modern Management Science. 2017(03):90-93. (in Chinese) 